\title{
Avoidable attendance at Accident and Emergency by the elderly in Hong Kong
}

\author{
EMC Lau, J Woo, JTS Chan
}

\begin{abstract}
Summary
Twenty per cent of Accident and Emergency department attendance by the elderly in a regional hospital in Hong Kong were deemed 'avoidable' by the attending doctors. The 'avoidable' attendants were younger and physically more independent than the appropriate attendants, and more of them were illiterate. Half of them attended the Accident and Emergency department for somatic complaints. Strategies to reduce these 'avoidable' attendances should be formulated.
\end{abstract}

Keywords: Accident and Emergency attendance, elderly

The total population of Hong Kong is 6 million, with $9 \%$ of the population being 65 years and older. There is 1.1 registered medical doctor and 4.4 hospital beds per 1000 population, compared to corresponding figures of 1.4 medical doctors and 6.4 hospital beds per 1000 in the UK. ${ }^{1}$ Currently, both Accident and Emergency (A\&E) and in-patient care hospital services are operated by the Hong Kong Hospital Authority, while public health services and primary healthcare clinics are managed by the Department of Health. The total health service expenditure in Hong Kong is one of the lowest in the world, being $3.7 \%$ of the gross national product. ${ }^{1}$ However, with a rapidly ageing population, the demands on the medical and health services in Hong Kong are constantly rising. In 1994, there were 1.6 million new consultations in local A\&E departments, with $14 \%$ of attenders being elderly ( 65 years and older). ${ }^{1}$ Such observations are similar to those in the US, where the proportion of patients attending the $A \& E$ department who are elderly was found to be higher than that in the general population. ${ }^{2,3}$ While some overseas studies have shown that a proportion of $A \& E$ attendance are not true emergencies, ${ }^{4,5}$ other investigators do not share this view. ${ }^{6-8}$ Information on 'avoidable' $A \& E$ attendance by the elderly is essential for service planning. This study was designed to document the extent of 'avoidable' A\&E attendance by the elderly in Hong Kong, and to examine factors associated with such attendance.

\section{Subjects and methods}

A cross-sectional survey was conducted in the $A \& E$ department of the Prince of Wales
Hospital, which is a regional hospital with 1372 beds serving 1.5 million people in Hong Kong. All patients attending the A\&E department are routinely classified into urgent and nonurgent categories by the medical staff and then managed separately. During one week in September 1995 all 'nonurgent' patients who were 65 years and over were included in the study.

A standardised, structured questionnaire was administered by trained student interviewers. The questionnaire was designed to obtain the following data: age, sex, educational level, adequacy of income, the activities of daily living, availability of help in case of emergency, and whether the subjects usually visited the doctor alone. Physical independence was assessed by finding out whether the study subjects could perform the following 10 activities without help: feeding, grooming, dressing, transfer, walking, climbing stairs, toileting, and bathing, and whether they were continent of urine and faeces. A score of one was given for each positive answer. Subjects were also interviewed on their main reason for attending A\&E. Finally, the attending doctor was asked to classify the $\mathrm{A} \& \mathrm{E}$ consultations as 'necessary' or 'avoidable'.

Student's $t$-test was used for comparing numerical characteristics and the chi-square test for comparing binary characteristics of patients whose attendances were considered 'necessary' or 'avoidable'.

\section{Results}

There were a total of 595 A\&E consultations by the elderly in the study period, $38 \%$ of whom were classified as nonurgent. Of these 226 subjects, $98 \%$ consented to be studied, $20 \%$ of whom were described as 'avoidable' by the attending doctor. In most instances, the patients who were classified as 'avoidable' by the attending doctors suffered from vague, nondisabling complaints for which no immediate treatment was required.

The characteristics of the two groups are shown in table 1 . There were no significant differences in the distribution by sex, marital status nor the proportion of subjects who lived alone between the two study group. The percentages of subjects who claimed that their income was not enough to live on were also similar. However, $50 \%$ of the 'avoidable' attendants claimed to be illiterate, and this figure was much higher than for 'necessary' attendants. According to census results, 52\% 
Table 1 Characteristics of patients whose A\&E attendance was deemed 'necessary' or 'avoidable' by the attending physician

\begin{tabular}{|c|c|c|}
\hline Characteristic & $\begin{array}{l}\text { Necessary } \\
\text { attendants } \\
(n=174)\end{array}$ & $\begin{array}{l}\text { Avoidable } \\
\text { attendants } \\
(n=44)\end{array}$ \\
\hline Mean age (years) & 75 (SD 7) & $72 \star(S D 5)$ \\
\hline Male : female ratio & $38: 62$ & $32: 68$ \\
\hline Divorced/single/widowed (\%) & 57 & 52 \\
\hline Living alone (\%) & 10 & 11 \\
\hline $\begin{array}{l}\text { Claimed income not enough } \\
\text { to live on }(\%)\end{array}$ & 26 & 21 \\
\hline Illiterate (\%) & 39 & $50 \star \star$ \\
\hline $\begin{array}{l}\text { Dependent in activities of } \\
\text { daily living (\%) }\end{array}$ & 10 & $0^{\star \star}$ \\
\hline $\begin{array}{l}\text { Assistance during emer- } \\
\text { gency not available } \\
\text { from friends and family (\%) }\end{array}$ & 5 & $16^{\star \star}$ \\
\hline $\begin{array}{l}\text { Have to go to see doctor } \\
\text { alone (\%) }\end{array}$ & 22 & $57^{\star \star}$ \\
\hline
\end{tabular}

Table 2 Chief complaint of patients whose attendance was deemed 'avoidable' by the attending physician $(n=44)$

\begin{tabular}{ll}
\hline Chief complaint & Percentage \\
\hline Musculoskeletal pain & 25 \\
Abdominal pain & 14 \\
Bowel disturbances & 9 \\
Chest pain & 9 \\
Neck pain & 7 \\
Eye discomfort & 7 \\
Dizziness and giddiness & 5 \\
Others & 33 \\
\hline
\end{tabular}

of Hong Kong men and women aged 65 years and above had not received any formal education. Ten per cent of the 'necessary' attendants scored 7 or below for physical independence, while all of the 'avoidable' attendants scored 8 or above. Moreover, $16 \%$ of 'avoidable' attendants claimed that assistance from friends and relatives was not available during emergencies, and $57 \%$ usually went to the doctor alone. These proportions were significantly higher than in 'necessary' attendants (p $<0.05$ ).

The chief complaints of 'avoidable' attendants are summarised in table 2. Musculoskeletal pain, abdominal pain, bowel disturbances

1 Hong Kong Hospital Authority. Hospital authority statistical report 1993/94. Hong Kong, 1995; pp 70-4.

2 Strange GR, Chen EH, Sanders AB. Use of emergency departments by elderly patients: projections from a multidepartments by elderly patients: projections from a

3 Sanders AB. Care of the elderly in emergency departments: conclusions and recommendations. Ann Emerg Med 1992; 21: $830-4$.

4 Lowenstein SR, Crescenzi CA, Kern DC, et al. Care of the elderly in the emergency department. Ann Emerg Med 1986; 15: $528-35$. and chest pain, together these accounted for more than half of all the attendance.

\section{Discussion}

As in other countries, the A\&E service in Hong Kong face problems of over-utilisation and limitation of resources. The results of the present survey indicated that $20 \%$ of elderly attendants had problems which could be dealt with elsewhere. Moreover, 'avoidable' attendants were younger and physically more independent. A lack of social support, a lack of assistance to obtain medical consultation, and being illiterate were associated with 'avoidable' attendance. We have also found that a large proportion of 'avoidable' attendants had somatic complaints, as was observed in the USA. ${ }^{5}$

Hence, it seems that social factors are important determinants of 'avoidable' attendances at $A \& E$ departments in Hong Kong. Although many social factors are not immediately amenable to changes, much may be achieved by public health education and provision of continuing medical care to the elderly. Currently in Hong Kong, few patients have long-term relationships with general practitioners, and 'doctor hopping' is the usual practice. The establishment of a general practitioner system, which would provide continuing care, would enable the elderly to turn to their physicians for minor medical ailments and thus reduce the use of $A \& E$ services as a first resort by elderly patients. Some interim measures may also be effective. For instance, 'avoidable' A\&E patients could be channeled to elderly healthcare resource centres located close to $A \& E$ departments. Such centres would offer a comprehensive range of services for physical, functional, social, and mental health needs. Medical problems could be dealt with immediately, while subsequent service needs could be planned and coordinated. These centres could essentially be staffed by paramedical personnel, with a small number of medical staff as a backup. As there is quite a big discrepancy in pay between medical and paramedical staff in Hong Kong, such service provision may result in substantial savings. Studies into the feasibility and cost-effectiveness of such alternative forms of healthcare for the elderly would be most welcome.

We are grateful to Mrs Aprille Sham for assistance with data analysis. 5 Bassuk EL, Minden S, Apster R. Geriatric emergencies: psychiatric or medical. Am $\mathcal{F}$ Psychiatry $1983 ; 140: 539-42$.
Ettinger WH, Casani JA, Coon PJ, et al. Patterns of use of
the emergency department by elderly patients. $\mathcal{F}$ Gerontol the emergency depar

7 Baum SA, Rubinstein LZ. Old people in the emergency room: age-related differences in emergency department use and care. $\mathcal{F}$ Am Geriatr Soc 1987; 35: 398-404.

8 Stathers GM, Delpech V, Raftos JR. Factors influencing the presentation and care of elderly people in the emergency department. Med f Aust 1992; 156: 197-200. 